\title{
Comparison of Axillary and Supraclavicular Approach in Ultrasound-Guided Brachial Plexus Block
}

Bo-Byoung Seo', Young-Woo Kim², Jong-Min Kim², Mi-Young Lee ${ }^{3}$, Young-Ho Jang ${ }^{4}$, Sang-Hyun $\mathrm{Woo}^{2}$

${ }^{1}$ Department of Anesthesiology and Pain Medicine, W Hospital, Daegu, Korea

${ }^{2}$ Cheon \& Woo's Institute for Hand \&

Reconstructive Microsurgery, W Hospital,

Daegu, Korea

${ }^{3}$ Department of Preventive Medicine, Keimyung University School of Medicine, Daegu, Korea ${ }^{4}$ Institute of Cancer Rehabilitation and Convalescence, Yoonsung Hospital, Cheongdo, Korea

Received: July 30, 2014

Revised: September 2, 2014

Accepted: September 4, 2014

Correspondence to: Sang-Hyun Woo

Cheon \& Woo's Institute for Hand \&

Reconstructive Microsurgery, W Hospital,

1616 Dalgubeol-daero, Dalseo-gu, Daegu

704-953, Korea

TEL: +82-53-550-5000

FAX: $+82-53-552-4000$

E-mail: handwoo@hotmail.com

This is an Open Access article distributed under the terms of the Creative Commons Attribution Non-Commercial License (http://creativecommons.org/ licenses/bync/3.0/) which permits unrestricted noncommercial use, distribution, and reproduction in any medium, provided the original work is properly cited.
Purpose: We examined the success rate and adverse effects of ultrasound-guided axillary and supraclavicular approach brachial plexus block.

Methods: From December 2013 to February 2014, 580 cases of patients received ultrasound-guided axillary approach or supraclavicular approach brachial plexus block. All blocks were performed by one anesthesiologist under ultrasound visualization using $0.2 \%$ or $0.75 \%$ ropivacaine $1 \%$ lidocaine with epinephrine in 1:200,000 as the anesthetic mixture.

Results: Failure rate of ultrasound-guided brachial plexus block was $1.2 \%$ and $0.2 \%$ in axillary and supraclavicular approach, respectively. In supraclavicular approach brachial plexus block, Honer's syndrome was observed in $17.9 \%$, chest discomfort in $14.9 \%$, and arterial puncture in $1 \%$. There was no adverse effect in axillary approach brachial plexus block.

Conclusion: Ultrasound-guided brachial plexus block serves higher success rate and lower occurrence rate of adverse effect and makes it useful for hand and upper extremity surgery. Supraclavicular approach has relatively higher success rate and lower rate of adverse effect than axillary approach.

Keywords: Brachial plexus block, Axillary approach, Supraclavicular approach, Ultrasound

\section{서론}

상완신경총 차단술(brachial plexus block, BPB)은 상완신 경총 주위에 국소마취제를 주사하여 팔, 손목, 손 등의 수술 시 전신마취를 대신할 수 있는 유용한 부위마취 방법이다. 그
러나 $\mathrm{BPB}$ 시술 시 혈관천자, 기흉, 호흡부전, 신경 손상 등의 합병증들이 발생될 수 있어 시술에 주의를 요한다. 쇄골상 접 근법은 상완을 포함한 상지 전체의 수술에 적용할 수 있으며, 신경이 조밀하게 모여 있기 때문에 시술도 비교적 용이하다. 그러나 여러 다른 신경이 인접해 있기 때문에 합병증의 발생 
률이 상대적으로 높다. 그에 반해 액와 접근법은 주로 팔꿈치 아래의 수술 시 사용할 수 있으며 합병증 발생률은 비교적 낮 으나, 신경이 분산되어 있기 때문에 시술을 어렵게 한다. 한편 해부학적 지표를 이용하는 고전적인 $\mathrm{BPB}$ 시행은 불완전한 마 취가 가능하며, 그 성공률은 약 $90 \%$ 대 초반으로 보고되고 있 다. 따라서 30 여 년 전부터 $\mathrm{BPB}$ 시술의 성공률을 높이고 합 병증을 감소시키기 위하여 신경자극기 ${ }^{3}$ 혹은 초음파 ${ }^{4}$ 를 사용 한 $\mathrm{BPB}$ 가 시행되었다. 그러나 신경자극기 사용 시 바늘 자체 가 신경 손상을 초래할 수 있는 부작용이 있으며 ${ }^{5}$, 비침습적인 초음파를 이용함에도 기흥 등의 합병증 발생이 여전히 보고되 어 있다. ${ }^{6}$ 이에 저자들은 수부 및 상지 수술 시 초음파 유도하 액와 접근법 및 쇄골상 접근법에 의한 $\mathrm{BPB}$ 의 성공률과 합병 증을 조사하고자 하였다.

\section{대상 및 방법}

2013년 12월부터 2014년 2월까지 초음파 유도하에 액와 접 근법 및 쇄골상 접근법으로 $\mathrm{BPB}$ 를 시행한 총 580 명의 환자들 을 대상으로 하였으며, 모든 시술은 단일 시술자에 의하여 시 행되었다. 쇄골상 접근법의 경우 인접한 횡경막 신경에 영향 을 줄 수 있기 때문에 환자의 과거력, 폐기능, 비만도, 흥부엑 스선사진 결과 및 수술 범위에 따라 접근 방법을 결정하였다. 기존의 호흡기 질환이 있는 경우, 수술 전 1초간 노력성 호기 량(forced expiratory volume in 1 second) 또는 노력성 폐활 량(forced vital capacity)이 30\% 이상 감소되어 있는 경우, 높은 비만도로 인하여 픽위키안 증후군(pickwickian syndrome)이 예상되는 경우, 흉부엑스선사진상 이상이 있는 경 우, 위팔 후내측(posteromedial side of upper arm)이 수술 범위에 포함되어 있는 경우 액와부 접근법(axillary approach)을 시행하였으며, 그 외에는 쇄골상부 접근법 (supraclavicular approach)을 시행하였다.

초음파 영상은 linear type의 초음파 프로브를 이용하여 시 행되었다(SonoAce R7, Samsung medison Co., Seoul, Korea). 액와 접근법(axillary approach, $\mathrm{AA}$ 군)에 의한 $\mathrm{BPB}$ 는 초음파로 상완골, 광배근, 및 액와동맥을 확인한 후 근육피 부신경(musculocutaneous nerve) 주변에 마취약제를 투여 한 다음 정중신경, 요골신경, 척골신경의 순서로 마취약제를 투여하였다. 쇄골상 접근법(supraclavicular approach, SA 군)에 의한 $\mathrm{BPB}$ 는 초음파로 쇄골상오목(supraclavicular fossa)에서 쇄골하동맥, 제 1 늑골, 전사각근, 중사각근, 그리 고 상완신경총을 확인한 다음 쇄골하동맥과 상완신경총 사이 에 1-2 $\mathrm{mL}$ 의 마취약제를 우선 주사한 후 바늘 끝이 신경집 (nerve sheath) 내에 있다고 판단되면 수력분리법(hydrodissection)으로 $5 \mathrm{~mL}$ 씩의 마취약제를 추가 주사하였다. 매번 마취약제 투여 전에는 주사기 음압으로 혈관 천자 유무를 확 인하였다. 가장 접근이 어려운 부위인 제 1 늑골, 쇄골하동맥, 아래신경줄기(inferior trunk) 사이에 약제가 고르게 분포되 면 프로브를 이동하여 중간신경줄기(middle trunk), 위신경 줄기(superior trunk)를 차례로 확인하면서 약제를 투여하였 다. 수술 범위에 따라 추가로 늑골사이위팔신경(intercostobrachial nerve) 차단이 필요한 경우는 본 연구대상에서 제외 하였다. 마취약제는 $2 \%$ 리도카인(lidocaine $\mathrm{HCl} 2 \%$ inj., DAI HAN PHARM. Co., Seoul, Korea) $20 \mathrm{~mL}$ 와 0.2\% 혹 은 $0.75 \%$ 로피바카인(ropivacaine $\mathrm{HCl} \cdot \mathrm{H}_{2} \mathrm{O} 2 \mathrm{mg} / \mathrm{mL}$ or $7.5 \mathrm{mg} / \mathrm{mL}$ inj., Han lim pharm. Co., Seoul, Korea) 20 $\mathrm{mL}$ 의 혼합 용액에 생리식염수 $10 \mathrm{~mL}$ 와 에피네프린 $0.1 \mathrm{mg}$ 을 섞어 사용하였다.

마취약제를 투여하고 시술 부위를 10 분간 압박한 후 요골신 경, 척골신경, 정중신경, 근육피부신경 지배 부위의 통증 및 운동을 관찰하였다. 각 부위에 핀셋으로 통증 유무를 확인하 여 차단 목표 신경 중 한 부위라도 통증이 있어 추가적인 차단 이 필요하거나 수술을 예정대로 진행할 수 없는 경우 마취 실 패로 판단하였으며, 이 경우 해당 신경 영역의 추가 마취나 수 술 부위에서의 국소마취 혹은 진정을 시행하였다. $\mathrm{BPB}$ 시행 후 동맥 천자, 호너증후군(Horner's syndrome) 및 흥부 불편 감 등의 합병증 발생 여부를 조사하였다. 마취로부터 회복 시 운동 기능이 먼저 회복되고 감각 기능이 뒤늦게 회복되기 때 문에, 수술 진행이 가능한 마취 유지 시간은 마취된 상지의 운 동 기능이 회복되는 것을 기준으로 조사하였다.

통계처리는 SPSS ver. 17.0 (SPSS Inc., Chicago, IL, USA) 프로그램을 이용하였으며, 각 군에서 평균 비교는 Student's t-test를 사용하였고, 빈도의 비교는 chi-square test를 사용하였으며, $\mathrm{p}$ 값이 0.05 미만인 경우를 통계학적 의 의가 있는 것으로 판정하였다.

\section{결과}

연구기간 동안 총 580 건의 $\mathrm{BPB}$ 가 시행되었으며, 이 중 $\mathrm{AA}$ 군은 84건, SA군은 496건이었다. 환자의 평균 연령은 $46.9 \pm$ 14.6세였으며, $\mathrm{AA}$ 군에서 여성에 비하여 남성의 빈도가 의의 있게 높았다(p<0.01) (Table 1). BPB 시행 시 총 주입된 마취 약제의 양은 $\mathrm{AA}$ 군이 $49.1 \pm 3.8 \mathrm{~mL}, \mathrm{SA}$ 군이 $38.8 \pm 5.7 \mathrm{~mL}$ 로 $\mathrm{AA}$ 군에서 의의있게 많았다(p<0.001). 마취유지 시간은 평

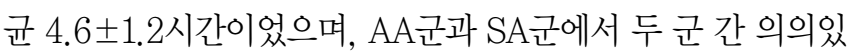


J Korean Soc Surg Hand Vol. 19, No. 3, September 2014

는 차이는 없었다( $p>0.05)$.

초음파하 시행된 580 건의 $\mathrm{BPB}$ 중 2건에서 불완전한 마취 가 되어 전체 실패율은 $0.3 \%$ 이었으며, $\mathrm{AA}$ 군과 $\mathrm{SA}$ 군에서 각 각 1 건으로 실패율은 $\mathrm{AA}$ 군이 $1.2 \%$, SA군이 $0.2 \%$ 이었으며, 두 군 간 통계학적으로 의의있는 차이는 없었다(Table 2). AA 군의 불완전한 마취는 요골신경 영역에서, $\mathrm{SA}$ 군의 불완전한 마취는 척골신경 영역에서 발생되었다. 불완전한 마취가 발생 한 두 경우 진정제의 투여와 추가적인 국소마취로 마취를 유 지할 수 있었다.

$\mathrm{BPB}$ 시행 후 $\mathrm{SA}$ 군의 143 명(28.8\%)에서 호너증후군, 흥부 불편감, 동맥 천자 등의 합병증이 발생되었다. 호너증후군이 나 흥부 불편감이 단독으로 발생한 경우는 각각 68 건, 53 건이 었으며, 21 건에서는 호너증후군과 흥부 불편감이 동시에 나타 났다(Table 3). 호너증후군은 89건에서 발생되었으며, 마취 회복 시 자연적으로 모두 소실되었다. 흥부 불편감을 호소한 74 명 모두 증상은 경미하였으며 69 명은 별다른 조치가 필요 없었고, 5 명은 약간의 두부 거상으로 불편감이 해소되었으며 모두 마취 회복 후 증상이 소실되었다. 동맥 천자가 발생한 5 명의 경우 10 분간 시술 부위를 압박 지혈함으로써 혈종은 발 생하지 않았다. 시술 후 기흉의 발생이 의심될 만한 증상은 한
건도 발생하지 않았다. $\mathrm{AA}$ 군에서는 동맥천자와 같은 시술 합 병증이 나타나지 않았다.

\section{고찰}

$\mathrm{BPB}$ 는 해부학적 시술 위치에 따라 사각근간(interscalene), 쇄골상, 쇄골하, 및 액와 접근법의 네 가지 형태로 시행되는데 이는 수술 부위에 따라 선택된다. 이 중 액와 접근법을 이용한 $\mathrm{BPB}$ 는 상완신경총 하단부를 마취하여 팔꿈치 이하의 수술에 흔히 사용되는 부위마취이며 다른 접근법에 의한 $\mathrm{BPB}$ 에 비하 여 기흥 및 호흡곤란 등의 부작용이 없는 가장 안전한 접근법 이다. 쇄골상 접근법에 의한 $\mathrm{BPB}$ 는 어깨 및 상완골 하단 부위 부터의 수술에 용이하며 마취발현시간이 빠르나 기흥 혹은 호 흡부전 등의 합병증이 발생될 수 있다. 비록 위의 두 가지 접 근법에 의한 마취가 비교적 안전하고 합병증이 적긴 하나 전 신마취와는 달리 불완전한 마취의 가능성이 있다. 따라서 약 30 여년 전부터 해부학적 지표를 이용한 $\mathrm{BPB}$ 의 실패율 및 합 병증을 감소시키기 위하여 신경자극기를 이용한 시술이 시도 되었으나 신경자극기를 사용하는 경우 환자의 불편감과 자극 에 의한 통증이 있을 수 있다. 이후 1994년에는 Kapral 등이

Table 1. Demographic data

\begin{tabular}{lcccc} 
Parameters & Total $(\mathrm{n}=580)$ & Group $\mathrm{AA}(\mathrm{n}=84)$ & Group $\mathrm{SA}(\mathrm{n}=496)$ & $\mathrm{p}$-value \\
Age (yr) & $46.9 \pm 14.6$ & $48.7 \pm 16.8$ & $46.6 \pm 14.1$ & $>0.05$ \\
Sex (male/female) & $306 / 274$ & $57 / 27$ & $249 / 247$ & $<0.01$ \\
Injected volume (mL) & $40.3 \pm 6.5$ & $49.1 \pm 3.8$ & $38.8 \pm 5.7$ & $<0.001$ \\
Anesthetic duration (hr) & $4.6 \pm 1.2$ & $4.6 \pm 1.3$ & $4.6 \pm 1.2$ & $>0.05$ \\
\hline
\end{tabular}

Values are means \pm standard deviation except sex (number of cases).

Group AA, axillary approach brachial plexus block; group SA, supraclavicular approach brachial plexus block; p-value, group AA ws. group SA.

Table 2. Incomplete anesthesia and its involved nerve and management

\begin{tabular}{lccll} 
Group & No. of cases & Failure rate (\%) & Failed nerve & Management \\
Group AA $(n=84)$ & 1 & 1.2 & Radial nerve & Sedative \\
Group SA $(n=496)$ & 1 & 0.2 & Ulnar nerve & Local injection and sedative \\
\hline
\end{tabular}

No significant difference in success rate between two groups.

AA, axillary approach brachial plexus block; SA, supraclavicular approach brachial plexus block.

Table 3. Adwerse events after supraclavicular approach brachial plexus block

$\begin{array}{lcc}\text { Events } & \text { Group AA (n=84) } & \text { Group SA (n=496) } \\ \text { Horner's syndrome } & - & 68(13.7 \%) \\ \text { Chest discomfort } & 0 & 53(10.6 \%) \\ \text { Horner's syndrome \& chest discomfort } & 0 & 21(4.2 \%) \\ \text { Artery puncture } & 0 & 5(1 \%)\end{array}$

AA, axillary approach brachial plexus block; SA, supraclavicular approach brachial plexus block. 
초음파를 이용한 쇄골상 접근법 $\mathrm{BPB}$ 를 최초로 시행하여 성공 률이 $95 \%$ 였음을 보고하였다. 근래에는 초음파를 사용하여 $\mathrm{BPB}$ 를 시행하여 환자의 불편함을 줄임과 동시에 성공률이 높 고 합병증을 감소시킬 수 있어 이의 사용이 선호되고 있다.

일반적으로 초음파를 이용하여 $\mathrm{BPB}$ 를 시행할 경우 해부학 적 지표에 의하여 시행하는 경우보다 성공률이 상당히 증가되 는데 시술 위치나 대상 환자 수, 시술자의 숙련도 등에 따라 다소 차이가 있으나 약 95\%-100\% 정도의 성공률이 보고되고 있다 ${ }^{8-10}$. 본 연구 결과 총 580 건의 초음파 하 $\mathrm{BPB}$ 의 성공률은 $99.7 \%$ 이었으며, 액와 접근법 및 쇄골상 접근법에 의한 $\mathrm{BPB}$ 성공률이 각각 $98.8 \%$ 와 $99.8 \%$ 로 나타났다. 이러한 결과는 해 부학적 지표를 이용한 Thompson 등메 의한 액와 접근법 및 쇄골상 접근법의 $\mathrm{BPB}$ 성공률이 $83.5 \%$ 이었고, Pearce 등의 액와 접근법에 의한 $\mathrm{BPB}$ 성공률이 $92.5 \%$ 이었음을 비교하여 볼 때 초음파의 사용이 $\mathrm{BPB}$ 의 성공률을 유의하게 증가시킴을 알 수 있다. 본 대상 환자들의 불완전한 마취가 된 두 경우에 서도 진정제 투여 및 국소마취를 추가 시행함으로써 전신마취 를 시행하지 않고 수술을 성공적으로 시행할 수 있었다.

$\mathrm{BPB}$ 성공률에는 마취약제의 양과 농도가 중요한 요인으로 작용하는데 이 중에서 마취약제의 양이 보다 중요한 요인이 된다. 초음파를 사용함으로써 $\mathrm{BPB}$ 시 사용되는 국소마취제 양을 효과적으로 줄일 수 있다 ${ }^{12,13}$. 일반적으로 국소마취의 성 공률은 $95 \%$ 이상을 기준으로 보는데 Song 등븐 초음파 유 도하 쇄골상 접근법에 의한 $\mathrm{BPB}$ 시 $95 \%$ 이상에서 마취가 되 는 최소효과용량은 $17 \mathrm{~mL}$ 라고 하였다. 그러나 일반적으로 쇄 골상 접근법과 액와 접근법에 의한 $\mathrm{BPB}$ 시 약 30-40 mL 정 도의 마취약제가 사용되는데 ${ }^{15,16} \mathrm{Jeon}$ 등 $^{17}$ 은 초음파 하 쇄골 상 접근법에 의한 $\mathrm{BPB}$ 시 $30 \mathrm{~mL}$ 를 사용한 경우 $90 \%$ 이상의 마취 성공률이 되므로 이의 용량을 권장하였고, Lo 등 18 은 평 균 $40 \mathrm{~mL}$ 의 마취약제를 사용하였다고 보고하였다. 본 대상 환자들에서는 평균 $40 \mathrm{~mL}$ 의 마취약제가 투여되었는데 쇄골 상 접근법에 의한 $\mathrm{BPB}$ 시 액와 접근법에 비하여 보다 적은 양 의 마취약제가 사용되었다.

한편 $\mathrm{BPB}$ 는 시술 부위에 따라 다르지만 다양한 합병증들이 발생될 수 있다. 이 중 호너증후군은 $\mathrm{BPB}$ 시술 동측의 교감신 경 차단에 의하여 흔히 나타나는 증후군으로 사각근간 접근법 에 의한 $\mathrm{BPB}$ 시에는 대부분 나타나며 쇄골상 접근법의 경우 에는 약 10\%-40\% 정도로 발생된다 ${ }^{19,20}$. 호너증후군은 비록 심 각한 후유증이 발생되는 합병증은 아니지만 환자에게 불쾌감 을 줄 수 있다. 본 연구 결과 초음파하 쇄골상 접근법에 의한 $\mathrm{BPB}$ 시행 후 호너증후군은 89 건에서 발생되어 $17.9 \%$ 의 빈도 를 나타내었으며, 이는 Gamo 등 ${ }^{19}$ 과 Tran 등 ${ }^{20}$ 의 보고와 비슷
한 빈도로 발생되었다.

$\mathrm{BPB}$ 시 호흡부전 혹은 흥부 불편감이 나타날 수 있는데 이 는 상완신경총과 인접한 횡경막 신경의 차단에 의하여 발생된 다. 사각근간 접근법에 의한 $\mathrm{BPB}$ 시에는 횡경막 신경 마비가 대부분 발생되며 쇄골상 접근법에 의한 $\mathrm{BPB}$ 시에는 최고 $67 \%$ 까지 발생한다고 보고되어 있다 ${ }^{21}$. 본 연구에서는 쇄골상 접근법에 의한 $\mathrm{BPB}$ 를 시행한 환자의 $14.9 \%$ 에서 흥부 불편감 을 호소하였다. 그러나 이들 환자들 모두의 증상은 경미하여 정서적 지지 및 두부 거상으로 마취를 유지할 수 있었으며 마 취 회복 시 증상이 모두 소실되었다.

호너증후군이나 흥부 불편감 등의 합병증은 투여한 약제가 상완신경총 주변의 별신경절이나 횡경막 신경으로 번져서 나 타나는 합병증으로 약물의 용적과 관계가 있을 수 있다. 그러 나 시술시 바늘이 움직이는 과정에서 근막을 따라 해당 신경 으로 번지는 경우도 많기 때문에 약물의 용적과 합병증의 상 관 관계에 대해서는 좀 더 연구가 필요할 것으로 생각된다.

한편 상완신경총이 해부학적으로 폐에 가까이 위치하여 기 흥이 발생될 수 있는데 해부학적 지표로 $\mathrm{BPB}$ 를 시행한 경우 그 발생 빈도는 $0.5 \%-6 \%$ 정도로 다양하게 보고되어 있다. 그 러나 초음파를 이용하여 해부학적 구조물을 정확히 파악하고 바늘의 위치를 정확히 보면서 $\mathrm{BPB}$ 를 시행함으로써 기흥의 발 생을 상당히 줄일 수 있는데, Gauss 등22은 초음파를 이용하여 쇄골 상부에서 신경 차단을 시행한 경우 기흥의 발생이 $0.06 \%$ 이었음을 보고하였다. 본 연구 대상 환자들에서는 기흥 이 단 한 건도 발생되지 않았다.

\section{결론}

초음파 유도하 상완신경총 차단술은 성공률이 매우 높고 합 병증 발생률이 적어 수부 및 상지 수술에 매우 유용한 마취 방 법이다. 성공률, 시술의 용이성 및 약제 투여량을 고려하여 쇄 골상 접근법을 기본으로 사용하며, 수술 전 환자 상태에 따라 합병증 발생이 예상되는 경우 액와 접근법을 사용할 수 있다. 그리고 빈도는 극히 적지만 호흡부전 혹은 기흥과 같은 합병 증이 발생 가능성이 여전히 존재하므로 시술함에 있어 항상 신중하여야 할 것이다.

\section{REFERENCES}

1. Lim EK, Pereira R. Brachial plexus injury following brachial plexus block. Anaesthesia. 1984;39:691-4.

2. Pearce H, Lindsay D, Leslie K. Axillary brachial plexus 
block in two hundred consecutive patients. Anaesth Intensive Care. 1996;24:453-8.

3. Smith BL. Efficacy of a nerve stimulator in regional analgesia; experience in a resident training programme. Anaesthesia. 1976;31:778-82.

4. Kapral S, Krafft P, Eibenberger K, Fitzgerald R, Gosch M, Weinstabl C. Ultrasound-guided supraclavicular approach for regional anesthesia of the brachial plexus. Anesth Analg. 1994;78:507-13.

5. Fanelli G, Casati A, Garancini P, Torri G. Nerve stimulator and multiple injection technique for upper and lower limb blockade: failure rate, patient acceptance, and neurologic complications. Study Group on Regional Anesthesia. Anesth Analg. 1999;88:847-52.

6. Bhatia A, Lai J, Chan VW, Brull R. Case report: pneumothorax as a complication of the ultrasound-guided supraclavicular approach for brachial plexus block. Anesth Analg. 2010;111:817-9.

7. Yuan JM, Yang XH, Fu SK, et al. Ultrasound guidance for brachial plexus block decreases the incidence of complete hemi-diaphragmatic paresis or vascular punctures and improves success rate of brachial plexus nerve block compared with peripheral nerve stimulator in adults. Chin Med J (Engl). 2012;125:1811-6.

8. Perlas A, Lobo G, Lo N, Brull R, Chan VW, Karkhanis R. Ultrasound-guided supraclavicular block: outcome of 510 consecutive cases. Reg Anesth Pain Med. 2009;34: 171-6.

9. O'Donnell BD, Ryan H, O'Sullivan O, Iohom G. Ultrasound-guided axillary brachial plexus block with 20 milliliters local anesthetic mixture versus general anesthesia for upper limb trauma surgery: an observerblinded, prospective, randomized, controlled trial. Anesth Analg. 2009;109:279-83.

10. Ootaki C, Hayashi H, Amano M. Ultrasound-guided infraclavicular brachial plexus block: an alternative technique to anatomical landmark-guided approaches. Reg Anesth Pain Med. 2000;25:600-4.

11. Thompson AM, Newman RJ, Semple JC. Brachial plexus anaesthesia for upper limb surgery: a review of eight years' experience. J Hand Surg Br. 1988;13:195-8.

12. O’Donnell B, Riordan J, Ahmad I, Iohom G. Brief reports: a clinical evaluation of block characteristics using one milliliter $2 \%$ lidocaine in ultrasound-guided axillary brachial plexus block. Anesth Analg. 2010;111: 808-10.

13. Marhofer P, Eichenberger U, Stockli S, et al. Ultrasonographic guided axillary plexus blocks with low volumes of local anaesthetics: a crossover volunteer study. Anaesthesia. 2010;65:266-71.

14. Song JG, Jeon DG, Kang BJ, Park KK. Minimum effective volume of mepivacaine for ultrasound-guided supraclavicular block. Korean J Anesthesiol. 2013;65:37-41.

15. Tran de QH, Dugani S, Correa JA, Dyachenko A, Alsenosy N, Finlayson RJ. Minimum effective volume of lidocaine for ultrasound-guided supraclavicular block. Reg Anesth Pain Med. 2011;36:466-9.

16. Bernucci F, Gonzalez AP, Finlayson RJ, Tran de QH. A prospective, randomized comparison between perivascular and perineural ultrasound-guided axillary brachial plexus block. Reg Anesth Pain Med. 2012;37: 473-7.

17. Jeon DG, Kim SK, Kang BJ, Kwon MA, Song JG, Jeon SM. Comparison of ultrasound-guided supraclavicular block according to the various volumes of local anesthetic. Korean J Anesthesiol. 2013;64:494-9.

18. Lo N, Brull R, Perlas A, et al. Evolution of ultrasound guided axillary brachial plexus blockade: retrospective analysis of 662 blocks. Can J Anaesth. 2008;55:408-13.

19. Gamo K, Kuriyama K, Higuchi H, et al. Ultrasoundguided supraclavicular brachial plexus block in upper limb surgery: outcomes and patient satisfaction. Bone Joint J. 2014;96-B:795-9.

20. Tran de QH, Russo G, Munoz L, Zaouter C, Finlayson RJ. A prospective, randomized comparison between ultrasound-guided supraclavicular, infraclavicular, and axillary brachial plexus blocks. Reg Anesth Pain Med. 2009;34:366-71.

21. Knoblanche GE. The incidence and aetiology of phrenic nerve blockade associated with supraclavicular brachial plexus block. Anaesth Intensive Care. 1979;7:346-9.

22. Gauss A, Tugtekin I, Georgieff M, Dinse-Lambracht A, Keipke D, Gorsewski G. Incidence of clinically symptomatic pneumothorax in ultrasound-guided infraclavicular and supraclavicular brachial plexus block. Anaesthesia. 2014;69:327-36. 


\section{초음파 유도하 상완신경총 차단에서 액와 접근법과 쇄골상 접근법의 비교}

서보병' - 김영우2 $\cdot$ 김종민 ${ }^{2} \cdot$ 이미영 ${ }^{3}$ 장영호 ${ }^{4} \cdot$ 우상현 ${ }^{2}$

'W(더블유) 병원 마취통증의학과, ${ }^{2}$ “천 앤 우’ 수부외과 및 미세재건수술센터, ${ }^{3}$ 계명대학교 의과대학 예방의학교실, ${ }^{4}$ 윤성 병원

목적: 초음파 유도하 액와 접근법 및 쇄골상 접근법에 의한 상완신경총 차단(brachial plexus block, BPB)의 성공률과 합병증을 조사하고자 하였다.

방법: 2013년 12월부터 2014년 2월까지 총 580건에서 초음파 유도하 액와 접근법 및 쇄골상 접근법에 의한 $\mathrm{BPB}$ 가 시 행되었다. 모든 $\mathrm{BPB}$ 는 한 명의 마취통증의학과 의사에 의하여 시행되었다. $\mathrm{BPB}$ 는 $0.2 \%$ 혹은 $0.75 \%$ 로피바카인과 $1 \%$ 리도카인 혼합 용액에 1: 200,000 에피네프린을 첨가하여 시행되었다.

결과: 초음파 유도하 $\mathrm{BPB}$ 의 실패율은 액와 접근법 시 $1.2 \%$, 쇄골상 접근법 시 $0.2 \%$ 이었다. 쇄골상 접근법에 의한 $\mathrm{BPB}$ 시 호너증후군이 $17.9 \%$, 흥부 불편감이 $14.9 \%$, 동맥 천자가 $1 \%$ 에서 발생되었다. 액와 접근법에 의한 $\mathrm{BPB}$ 시에 는 별다른 합병증이 발생되지 않았다.

결론: 초음파의 사용은 수부 및 상지 수술 마취 시 $\mathrm{BPB}$ 의 성공률을 높이고 합병증을 줄이는 유용한 방법이다. 쇄골상 접근법이 액와 접근법에 비하여 상대적으로 성공률이 높으며 합병증 발생률도 더 높다.

색인단어: 상완신경총 차단, 액와 접근법, 쇄골상 접근법, 초음파

접수일 2014년 7월 30일 수정일 2014년 9월 2일

게재확정일 2014년 9월 4일

교신저자 우상현

대구광역시 달서구 달구벌대로 1616,

$\mathrm{W}$ (더블유) 병원 '천 앤 우' 수부외과 및 미세재건수술센터

TEL 053-550-5000 FAX 053-552-4000

E-mail handwoo@hotmail.com 